\title{
Qualitative Research Framework: Integrating Philosophical and Methodological Assumptions
}

\author{
Md. Bayezid Alam \\ $\mathrm{PhD}$ Researcher, Faculty of Education, Beijing Normal University, China
}

\begin{abstract}
This study aims to integrate how philosophical assumptions relate to the chosen methodology, methods, research questions, and prospective outcomes. The study shows that the methods of data collection chosen for the research are influenced by the research methodology. In turn, the methodology is influenced by the theoretical perspectives and similarly, the theoretical perspective is influenced by the ontological and epistemological stance. It could be argued that the researcher's ontological and epistemological stances impact every aspects of the research process.
\end{abstract}

DOI: $10.7176 / \mathrm{JPCR} / 40-01$

\section{Introduction}

The methodological part is considered as the foundation of any research. It helps to understand the philosophical stance of the researcher. Crotty's (1998) ideas established the groundwork for the research framework. He suggested that an inter-relationship exists between the theoretical framework, the methodology and methods, and the philosophical stance. Based on Crotty's (1998) framework, researcher need to pay considerable attention on four questions for designing the research proposal: (i) What epistemology embedded in the theoretical framework? (ii) What theoretical framework lies behind the methodology in questions? (iii) What methodology governs researcher's choice and use of methods? (iv) What methods researcher propose to use? Making methodological part of any research more competent and seeking the answers of research questions, this paper attempts to explain theoretical framework, to lay out methodology, and to identify suitable methods according to the above understanding.

\section{Theoretical Framework}

The theoretical framework constitutes a strong scientific base and contributes as a map for the research (Lederman \& Lederman, 2015). Crotty (1998) defined theoretical framework as "the philosophical stance informing the methodology and thus providing a context for the process and grounding its logic and criteria" ( $\mathrm{p}$. 3). Without use of underlying theoretical framework, research can not be conducted (Broido \& Manning, 2002). It is grounded by the researcher's philosophical assumptions and is enabled developing the methodology and methods of the study. Researchers need to take a position regarding their perceptions of the world (ontological stance) and perceptions of the knowledge (epistemological stance). For example, 'realism' and 'social constructivism' can be ontological and epistemological stance respectively.

Ontologically, the constructivist orientation believes that reality is constructed by individuals in a particular social context (Jones, 2007). However, Crotty (1998) mentioned three epistemological ranges: (i) subjectivism, (ii) objectivism, and (iii) constructivism. In subjectivist epistemology, meaning (or truth) is created out of nothing but it is imposed on the object by the subject. In contrary, objectivist epistemology holds that meaning (or truth) exists with objectively. The epistemological stance, social constructivism, rejects both 'subjectivism' and 'objectivism' paradigm and takes sit between them. In constructivism, meaning (truth) comes from anything but an interaction between the subject and the object. From this constructivist point of view, researcher can investigate the social phenomenon.

Social constructivism underlies interpretive research. Ontologically, interpretivism assumes that reality is socially constructed through interaction of individuals (Walsham, 1995). Epistemologically, interpretivism relates to a subjectivist views, meanings and interpretation. Interpretivism supported scholars in terms of exploring their world by interpreting the understanding of individuals (Thanh \& Thanh, 2015). Grix (2004), however, argued that there is no distinction between natural and social worlds. Researchers are not detached from the subjects they are studying. They are just part of that social reality. Therefore, Carson et al. (2001) argued interpretive paradigm is more personal and flexible for capturing meanings in human interaction and making sense of what is perceived as reality. Wellington (2015) stated, "The interpretive researcher, however, accepts that the observer makes a difference to the observed and that reality is a human construct. The researcher's aim is to explore perspectives and shared meanings and to develop insights into situations" (p. 26).

Ontologically, positivism assumes that the social world is external. Epistemologically, in this framework, knowledge gained through the study of this world is leveled 'scientific' (Merriam, 2009) and the researchers remain detached themselves creating a distance from the participants. Positivism is only able to tackle 'what' and 'where' questions. It means positivism can capture states or conditions. On the other hand, 'social 
constructivism' and 'interpretivism' are able to explore the answer 'why' and 'how' this reality is constructed.

\section{Methodology}

Methodology refers to the strategy or plan of action. It shapes researcher's choice and use of particular methods and links them to the desired outcomes (Crotty, 1998). The methodology arises from the ontological and epistemological position of the researcher. It brings philosophical standpoint (on ontology and epistemology) and methods (perspective and tool) together for a given study (Hesse-Biber, 2017). The methodology and methods should be selected based on its ability to answer the specific research questions and attain the study objectives (Johnson \& Onwuegbuzie, 2004). For example, researcher can prefer qualitative research methodology which reflects his/her ontological and epistemological stance.

It could be argued that there is a strong connection between interpretive paradigm and qualitative methodology. Justification is found in different literatures - specially the scholar's analyses on the comparative advantages of qualitative and quantitative research approaches. Onwuegbuzie \& Leech (2005) argued that quantitative and qualitative research paradigms operate under different ontological and epistemological assumptions. Bryman (2004) remarked, qualitative research is broadly 'interpretivist' (epistemologically) and 'constructionist' (ontologically); whereas quantitative research is associated with 'positivism' (epistemologically) and 'objectivism' (ontologically). Mason (1996) stated that qualitative research is 'interpretivist' in the sense that it is concerned with how the social world is interpreted, understood, experienced and produced (p. 4). On the other hand, the quantitative approach simply manifests itself through mathematical means without interpretation of individual's perspective in particular social context. Crowe \& Sheppard (2010), however, argued that the research without interpretation is simply disaggregated. Furthermore, the qualitative research emphasizes on 'holistic' forms of analysis and explanation on the basis of rich, contextual and detailed data (Mason, 1996).

Quantitative approach seeks to reveal causal relationships using in survey research with a positivistic framework (Wazed, 2012). This approach will not be better suited to make clear understanding on the phenomenon without philosophical interpretation. Qualitative methods with an 'interpretivist' paradigm are used to understand the social world from the interpretations of the individuals who are part of the ongoing action being investigated (Cohen et al, 2000).

Interpretive researchers use different qualitative methodologies. Cresswell (2007) suggested five types of qualitative approaches: case study, phenomenology, grounded theory, ethnography, and narrative research. Bogdan \& Biklen (1982) argued case study is a detailed examination of one setting, or one single subject, or one single depository of documents, or one particular event. Ahmed et al. (2017) argued that, in a given research condition, a case study is well established to derive answers of 'how' and 'why' questions to generalize the phenomenon and this is the rationale of proposing this qualitative research methodology.

\section{Methods}

Methods refer the techniques or procedures allow us to gather and analyze data related to the particular research questions for learning about social reality (Crotty, 1998). These techniques are used to gather data from individuals, groups, and texts in any medium (Hesse-Biber, 2017). Qualitative research involves the studied using a variety of empirical methods such as personal experience, life story, interview, observational, historical, interactional, and visual (Denzin \& Lincoln, 1994). For example, the research questions require the use of qualitative methods including Focus Group Discussion (FGD), interviews, observations, and documents analysis to understand the individual's perceptions about the social world.

The FGD is routinely used as qualitative research methods in a wide variety of settings (Farnsworth \& Boon, 2010). FGD is one of the suitable ways to understand the social phenomenon. Interview is one of the dominant methods in qualitative research. Scholars considered the situation of the interview as a construction site of making knowledge (Flick, 2007). To explore the study, researcher can use in-depth face to face interviewing as method of data collection. The Key Informant Interview (KII) and observation can also be employed as method of data collection. Data can be collected through document analysis from different books, journals, working papers, newspapers, and reports etc.

After completing data collection process, researcher should analyze and present these data carefully to understand the phenomenon. In this stage, researcher can use three different techniques: (i) data reduction, (ii) data display, (iii) conclusion drawing and verification (Miles et al., 2014). By data reduction process he/she select, focus, and transform data. Then he/she present data in textual, tabular and graphical forms through data display process. Finally, he/she goes conclusion drawing and verification process which refers to the analyst's effort to give meaning to data.

\section{Conclusion}

This paper tried to demonstrate how philosophical assumptions relate to the chosen methodology, methods, research questions, and prospective outcomes. The analysis has clearly shown that the methods of data collection 
chosen for the research are influenced by the research methodology. In turn, the methodology is influenced by the theoretical perspectives and similarly, the theoretical perspective is influenced by the ontological and epistemological stance. It could be argued that the researcher's ontological and epistemological stances impact every aspects of the research process. Cunningham (2014, p. 32) argued that, "numerable elements - both philosophical (ontological and epistemological assumptions and theoretical perspective) and practical (issue to be addressed, purpose, aims and research questions) - are influential in the process of selecting a research methodology and methods, and that these elements and their inter-relationships must be considered and explicated to ensure a coherent research design that enables well-founded and meaningful conclusions'.

\section{References}

Ahmed, J. U., Ashikuzzaman, N. M., \& Mahmud, A. S. M. (2017). Social innovation in education: BRAC boat schools in Bangladesh. Journal of Global Entrepreneurship Research, 7(20), 1-14.

Bogdan, R., \& Biklen, S. (1982). Qualitative research for education. Boston: Allyn and Bacon.

Broido, E. M., \& Manning, K. (2002). Philosophical foundations and current theoretical perspectives in qualitative research. Journal of College Student Development, 43(4), 434-445.

Bryman, A. (2004). Social research methods. Oxford: Oxford University Press.

Crowe, M., \& Sheppard, L. (2010). Qualitative and quantitative research designs are more similar than different. The Internet Journal of Allied Health Sciences and Practice, 8(4), Article 5.

Cunningham, K . B. (2014). Social research design: framework for integrating philosophical and practical elements. Nurse Researcher, 22(1), 32-37.

Carson, D., Gilmore, A., Perry, C., \& Gronhaug, K. (2001). Qualitative marketing research. London: Sage Publications.

Crotty, M. (1998). The foundations of social research: Meaning and perspective in the research process. London: Sage Publications.

Creswell, J. W. (2014). Research design: Qualitative, quantitative and mixed methods approaches (4th ed.). Thousand Oaks, CA: Sage Publications.

Cornish, F., \& Gillespie, A. (2009). A pragmatist approach to the problem of knowledge in health psychology. Journal of Health Psychology, 14(6), 800-809.

Cohen, L., Manion, L., \& Morrison, K. (2000). Research methods in education, (5th ed.). London: Routledge.

Denzin, N., \& Lincoln, Y. (Eds.) (1994). Handbook of qualitative research., California: Sage Publications.

Flick, U. (2007). Designing qualitative research. London: Sage Publications.

Farnsworth, J., \& Boon, B. (2010). Analysing group dynamics within the focus group. Qualitative Research, $10(5), 605-624$

Grix, J. (2004). The foundations of research. London: Palgrave Macmillan.

Gray, D. E. (2004). Doing research in the real world. London: Sage Publications.

Hesse-Biber, S. N. (2017). The practice of qualitative research: Engaging students in the research process (3rd ed.). Thousand Oaks, CA: Sage Publications.

Jones, D. D. (2007). Making connections: The relationship between epistemology and research methods. The Australian Community Psychologist, 19(1), 19-27.

Johnson, R. B., \& Onwuegbuzie, A. J. (2004). Mixed methods research: A research paradigm whose time has come. Educational Researcher, 33(7), 14-26.

Lederman, N. G., \& Lederman, J. S. (2015). What is a theoretical framework? A practical answer. Journal of Science Teacher Education, 26, 593-597.

Merriam, S. B. (2009). Qualitative research: A guide to design and implementation. San Francisco, CA: JosseyBass.

Miles, M. B., Huberman, A. M., \& Saldana, J. (2014). Qualitative data analysis: A methods sourcebook (3rd ed.). Thousand Oaks, CA: Sage Publications.

Mason, J. (1996). Qualitative Researching. London: Sage Publications.

Onwuegbuzie, A. J., \& Leech, N. L. (2005). Taking the "Q" out of research: Teaching research methodology courses without the divide between quantitative and qualitative paradigms. Quality \& Quantity, 39(3), 267295.

Thanh, N. C., \& Thanh, T. T. (2015). The interconnection between interpretivist paradigm and qualitative methods in education. American Journal of Educational Science, 1(2), 24-27.

Wellington, J. (2015). Educational research: Contemporary issues and practical approaches. London \& New York: Bloomsbury Academic.

Wazed, S. (2012). Gender and social exclusion/inclusion: A study of indigenous women in Bangladesh (Doctoral Dissertation). University of Birmingham, Birmingham.

Walsham, G. (1995). The emergency of interpretivism in IS research. Information System Research, 6(4), 376394. 